\title{
Parotid mass, Metaplastic Whartin's Tumor case report
}

\author{
Güclü Kaan Beriat ${ }^{1}$, Cem Dogan ${ }^{1 *}$, Sefik Halit Akmansu' ${ }^{1}$, Omür Ataolu ${ }^{2}$ \\ ${ }^{1}$ Faculty of Medicine, Department of Otorhinolaryngology, Ufuk University, Ankara, Turkey \\ ${ }^{2}$ Mikro-Pat Pathology Laboratory, Ankara, Turkey \\ Email: kberiat4@gmail.com, ${ }^{*}$ cemdo78@yahoo.com, sefikhalitakmansu@yahoo.com, info@mikropat.com.tr
}

Received 28 July 2011; revised 21 December 2011; accepted 21 February 2012

\begin{abstract}
The Whartin Tumor is the second most frequent tumor of the parotid gland following pleomorphic adenoma. Among the Whartin tumors, Metaplastic Whartin Tumor (MWT) is rare. In case of a MWT, histopathological replacement of oncosytic cells by squamous cells, ruptured epidermoid and lymphoe-pithelial cystic areas, a large necrosis area, fibrosis and granuloma formation may be seen. MWT may display similar clinical characteristics as the malign parotid tumor that causes sialadenitis, abscess formation, skin ulceration, and facial paralysis. Although the histopathogenesis of Metaplastic Whartin Tumors is not exactly known, it is postulated that the histopathological processes caused by trauma, infection, or radiotherapy have a role in the formation of these tumors. This case study presents a 48-year-old female patient with a complaint of panicula before her left ear persisting for 5 months. Following a superfacial parotidectomy carried out 3 weeks after the fineneedle aspiration biopsy (FNAB), her pathological assessment was found to be in line with Metaplastic Whartin Tumor. Our case study presents the case of a Metaplastic Whartin Tumor case with a review of literature on the subject, accompanied by radiological and histological analyses.
\end{abstract}

Keywords: Head; Neck Cancer; Precancerous Conditions Oral; Maxillofacial Surgery

\section{INTRODUCTION}

The Whartin's tumor is the second most frequent tumor of the parotid gland following pleomorphic adenoma [1]. Whartin's tumors are classified into four histologic subgroups: the first three depending on the existence of changes in the epithelial-stromal components, and the fourth depending on the metaplastic-squamous changes [2]. The Metaplastic Whartin's Tumor (MWT), which is the fourth type, is rarely seen with a frequency of $6.2 \%$

"Corresponding author. among the Whartin's tumors [1]. With MWT cases, histopathological replacement of oncosytic cells by squamous cells, ruptured epidermoid and lymphoepithelial cystic areas, a large necrosis area, fibrosis and granuloma formation may be seen [1,3]. In some cases, however, following the fine-needle aspiration biopsy (FNAB) epithelioid granulomas, cholesterol clefts, and hemociderin deposits can be detected [4-6]. MWT may sometimes display similar clinical characteristics as the malignant parotid tumor that causes sialadenitis, abscess formation, purulent fistula, skin ulceration, and facial paralysis [712].

For the diagnosis of MWT a microscopic analysis with Hemotoxilin Eosin is generally sufficient. To differentiate between flat-cell and mucoepidermoid carcinoma is of utmost importance since these two might be confused histopathologically $[13,14]$.

\section{CASE REPORT}

A 48-year-old female patient presented to our ear, nose and throat clinic (ENT) with a swelling of panicula that was gradually getting bigger before her left ear persisting for 5 months. Physical examination revealed a mass which was $15 \times 20 \times 15 \mathrm{~mm}$ in size, and was rigid, semi-mobile, and a little sensitive to palpation. The rest of her ENT examination results were normal.

Parotid ultrasonography revealed a hypoechoic solid lesion with smooth borders that was circular in shape, and of $17 \times 20 \times 20 \mathrm{~mm}$ in size having septations and ecogenic solid component in the left parotid superficial lobe was reported. The FNAB showed oncosytic cells with single and three dimensional strata on a hemorrhagic and partly lymphocytic ground (Figures 1 and 2). With this result the patient was pre-diagnosed with Whartin's tumor.

Three weeks after the FNAB the patient underwent left superficial parotidectomy under general anesthesia. During the procedure it was seen that the mass had partial cystic formations and it was dissected from the tissues surrounding the parotitis with difficulty because of intense fibrosis. 


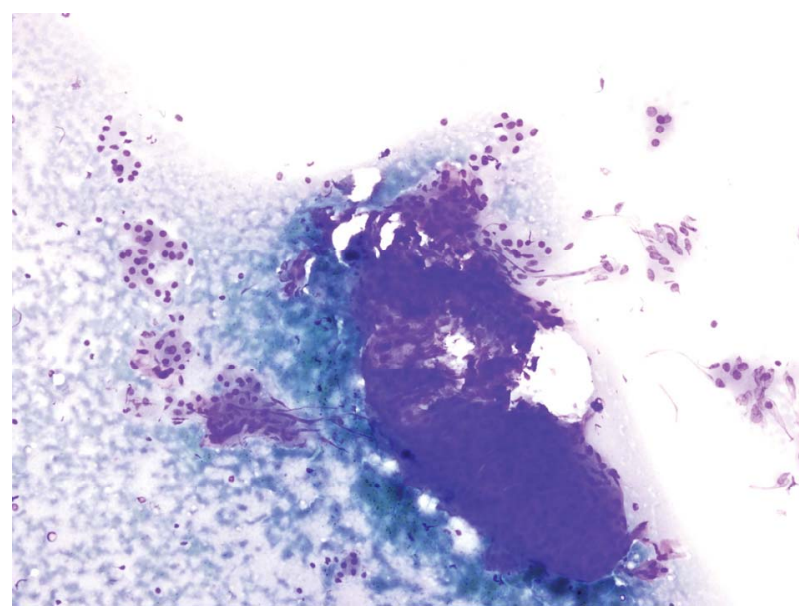

Figure 1. During the fine needle aspiration biopsy oncosytelike cells in small and partly three dimensional levels were seen $($ Giemza $\times 20)$.

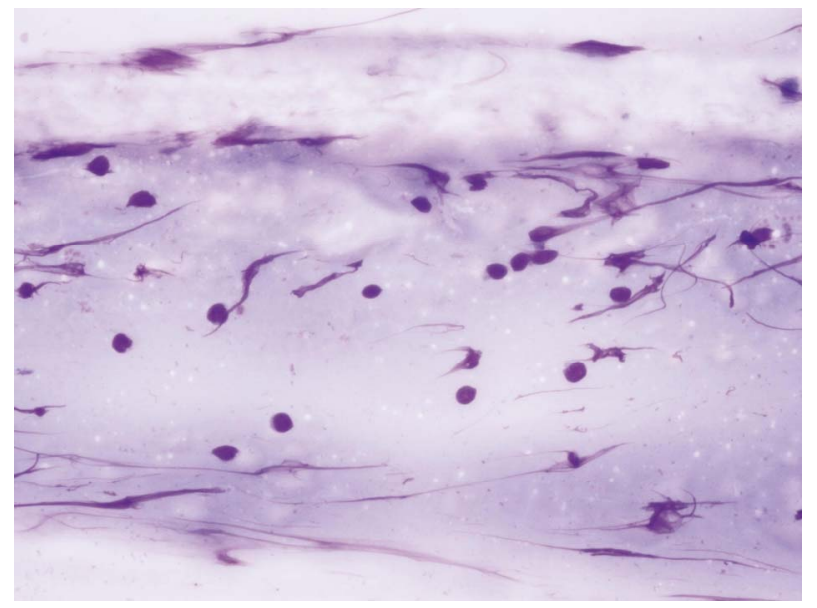

Figure 2. Lymphocytic ground of the fine needle aspiration biopsy (Giemza ×60).

Pathological analysis of the specimen revealed threedimensional solid structures formed by eosinophilic stoplasmal oncosytic structures. In some of the regions of these structures total infarct areas and papillary structures were detected. Further, characteristic squamous metaplasia and intense inflammation were seen in the surrounding tissues (Figures 3-6). As a result of this patho-logical evaluation the patient was diagnosed with Metaplastic Whartin's Tumor. After surgical therapy, the patient was irradiated with 3 cGy to the parotid region. No complications or relapses occurred during the one year postoperative follow-up period.

\section{DISCUSSION}

FNAB offers a high diagnostic gain in salivary gland lesions and is also a safe, fast, inexpensive, physicianfriendly, and an easily tolerable diagnostic method by patients. The most significant point regarding FNAB's

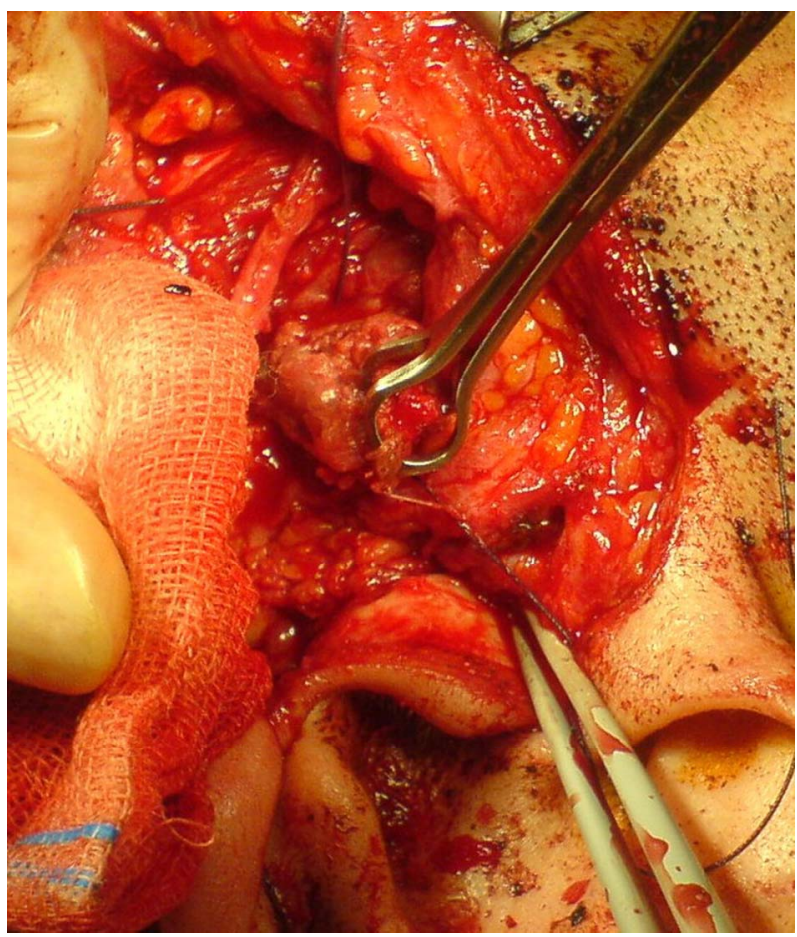

Figure 3. Areas with total infarct were seen in the parotid tissue $(\mathrm{HE} \times 10)$.

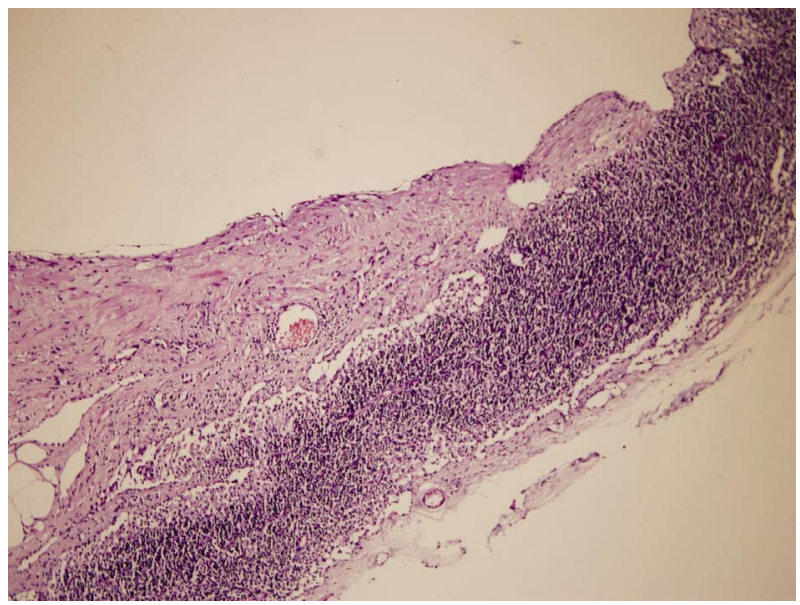

Figure 4. Solid structures created by the oncosytic cells with eosinophilic stoplasma and squamatous metaplastic regions here in between stand out $(\mathrm{HE} \times 10)$.

diagnostic importance in salivary glands is that it enables the pathologist to have a rate of $96 \%$ right diagnosis with its high sensitivity and specifity for all salivary gland tumors [15].

Malignant salivary gland tumors are histologically labile and structurally complex tumors. Epithelial, nonepithelial tumors, lymphomas, metastatic tumors, and non-neoplastic lesions are the malignant tumors of the salivary gland. This diversity makes it difficult to reach a diagnosis through cytological analysis [16].

FNAB has been shown to have $5.5 \%$ wrong positive 


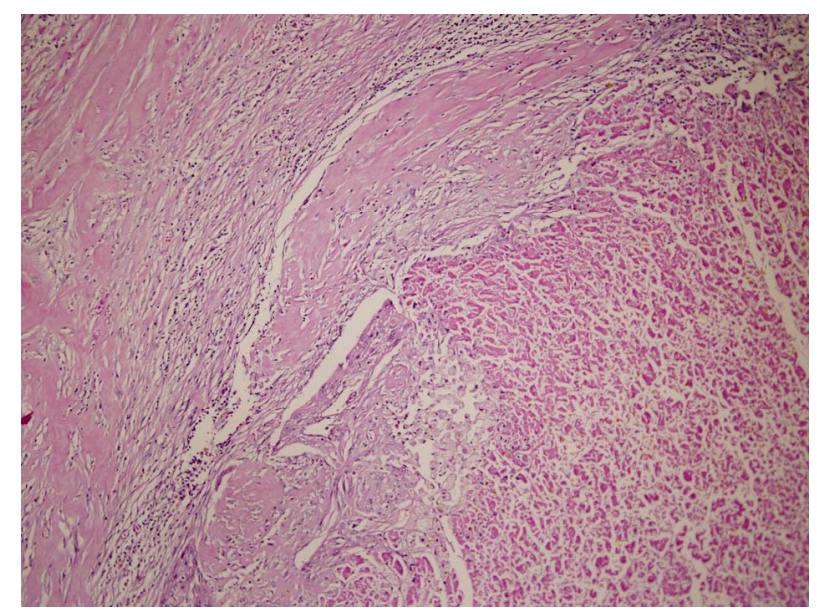

Figure 5. In a couple of areas intense lymphocytic cells in papillary structures and stroma within the infarcted regions were seen $(\mathrm{HE} \times 20)$.

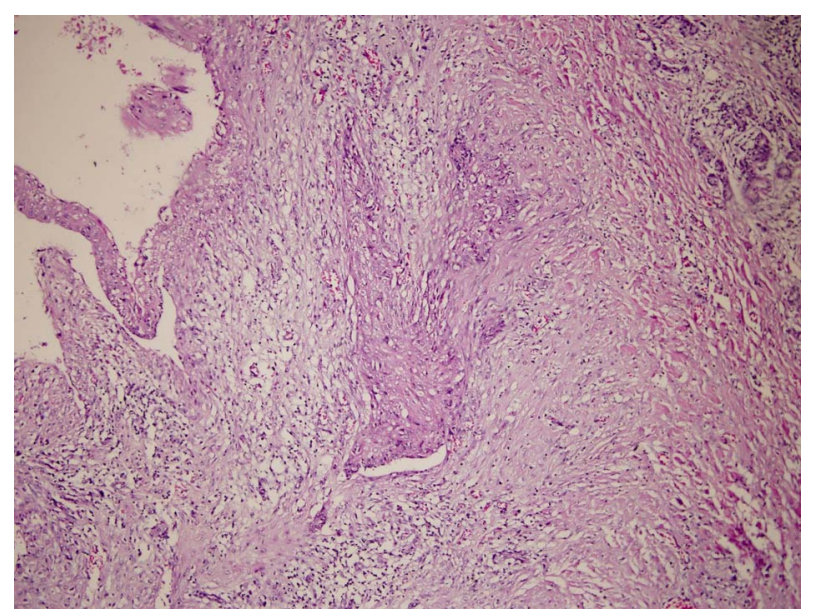

Figure 6. Intense lymphocytic cells in the stroma under the cystic cavity were detected $(\mathrm{HE} \times 4)$.

and $2.7 \%$ wrong negative rates with parotid masses [17]. Although there are limited number of cases, one of the disadvantages of FNAB is the tumor cultures seen along the needle tract [15]. Because of these FNAB's role in the diagnosis of malignant parotid masses is still questionable.

Although the histopathogenesis of Metaplastic Whartin's Tumors is not exactly known, it is argued that the histopathological processes caused by trauma, infection, or radiotherapy have a role in the formation of these tumors [18]. Most of the patients with Metaplastic Whartin's Tumor have a history of trauma because of FNAB (specifically FNAB), $[19,20]$ and a small portion of them, $20 \%-40 \%$, have a history of radiotherapy [2].

Especially the other tumors (hurthle cell adenoma of the thyroid) rich in oncosytic cells and mitochondria have also infarcts and squamous metaplasis of different levels following FNAB as is seen with this tumor [21-25].
Following the FNAB some changes may also take place in the inflammatory process of the tumor mass and the surrounding tissues [26]. As a result, inflammation and fibrosis may be seen around the facial nerve and xanthogranulomatous sialadenitis may develop $[9,27]$.

All these changes may be seen in other organs like the lungs, lymph node, and the thyroid besides the salivary glands following the FNAB [22,24,25]. Experimental trials conducted with rats' parotid tissues demonstrated that inflammatory processes as well as metaplastic changes start to take place in a couple of days when the arteries feeding the parotid are bound [28]. It has also been shown that the period for the development of squamous metaplasia is 6 to 101 days between the FNAB and the surgery $[3,29]$.

Squamous metaplasia cannot be seen in every Warthin's tumor where ischemia and necrosis occur. Moreover, metaplastic epithelium in metaplastic Warthin's tumor does not have atypical cytological features and infiltrating growth pattern [14].

Most of the reported cases of malignant transformation in Warthin's tumor did not show distant metastasis. However, local lymph node metastasis was reported [2].

Treatment of this tumor is primarily surgical, consisting of adequate excision of the primary site with or without neck dissection [30]. However, neither radiotherapy nor chemotherapy changed the prognosis, and these patients died earlier [31]. Surgeons usually use postoperative chemotherapy and radiotherapy if the histological type of the tumor is Adenocarcinoma [32].

The present case was diagnosed as having squamous metaplastic changes and intense inflamation, and underwent a superficial parotidectomy without neck dissection. After surgical therapy, the patient was irradiated with 3 cGy to the parotid region. The present case has a negative systemic screening for primary cancer, and no recurrence of the tumor for 1 year. The long-term prognosis of these patients is not clear.

Since there are no studies carried out with large case series regarding the frequency with which the FNAB causes metaplasia in patients with the Whartin's tumor, it has not been possible to point out to the details of this relation in full extent. It should not be disregarded, however, that all Metaplastic Whartin's Tumor patients do not have either a history of trauma or a history of FNAB [33]. But it should also be taken into consideration that with the patients diagnosed with the Whartin's tumor following a FNAB, inflammation and tissue changes based on necrosis during the surgery may very well be seen.

In terms of a differential diagnosis, it is also important to direct the attention of the pathologist to the metaplastic changes during the postoperative period with those patients with a history of FNAB who had under- 
gone surgery having been prediagnosed with the Whartin's tumor and who had difficulties of this kind during the surgery.

\section{REFERENCES}

[1] Eveson, J.W. and Cawson, R.A. (1989) Infarcted (infected) adenolymphomas. A clinicopathological study of 20 cases. Clinical Otolaryngology, 14, 205-210. doi:10.1111/j.1365-2273.1989.tb00362.x

[2] Seifert, G., Bull, H.G. and Donath, K. (1980) Histologic subclassification of the cystadenolymphoma of the parotid gland. Analysis of 275 cases. Virchows Arch A Pathol Anat, 388, 13-38.

[3] Seifert, G. (1991) Histological typing of salivary gland tumours. Springer-Verlag, Berlin, 13-14. doi:10.1007/978-3-642-84506-2

[4] Bungaard, N., Eriksen, H.E. and Greisen, O. (1987) Inflamed adenolymphoma with cholesterol granuloma. Journal of Laryngology \& Otology, 101, 967-970.

[5] DiPalma, S., Simpson, R.W.H., Skálová, A. and Michal, M. (1998) Metaplastic [infarcted] Warthins tumor: A possible consequence of fine needle aspiration biopsy. Arch Anat Cytol Path Clin Exp Path, 46, 433-438.

[6] Ryska, A. and Seifert, G. (1999) Adenolymphoma [Warthin's tumor] with multiple sarcoid-like granulomas. $\mathrm{Pa}$ thology Research and Practice, 195, 835-839. doi:10.1016/S0344-0338(99)80106-X

[7] Abraham, Z., Rozenbaum, M. and Keren, R. (2000) Skin ulcer at the blunt apex of a giant Warthin's tumor. Journal of Dermatology, 27, 523-528.

[8] Chilla, R. and Droese, M. (1993) Das infizierte Zystadenolymphom. Ein möglicher Anlaß zur klinischen und zytologischen Fehldiagnose "Karzinom". HNO, 41, 446448.

[9] Lesser, R.W. and Spector, I.G. (1985) Facial nerve paralysis associated with Warthin's tumor. Archives of Otolaryngology—Head \& Neck Surgery, 111, 548-549. doi:10.1001/archotol.1985.00800100096016

[10] Newman, L., Loukota, R.A. and Bradley, P.F. (1993) An infarcted Warthin's tumour presenting with facial weakness. British Journal of Oral and Maxillofacial Surgery, 31, 311-312. doi:10.1016/0266-4356(93)90067-7

[11] Patey, D. and Thackray, A.C. (1970) Infected adenolymphoma: A new parotid syndrome. British Journal of Surgery, 57, 569-572. doi:10.1002/bjs.1800570805

[12] Pinel, J., Narcy, P. and Trotoux, J. (1971) Cystadenolymphomes parotitidiens masques par une surinfection. Ann Otolaryngol Chir Cervicofacial, 88, 283-286.

[13] Seifert, G. (1997) Bilateral mucoepidermoid carcinomas arising in bilateral pre-existing Warthin's tumours of the parotid gland. European Journal of Cancer, 33, 284-287.

[14] Skalova, A., Michal, M. and Nathansky, Z. (1994) Epidermoid carcinoma arising in Warthin's tumour: A case study. Journal of Oral Pathology \& Medicine, 23, 330-333. doi:10.1111/j.1600-0714.1994.tb00070.x
[15] Palma, S.Di, Simpson, R.H.W., Skalova, A., Michal, M. (1999) Metaplastic (infarcted) Warthin's tumour of the parotid gland: A possible consequence of fine needle aspiration biopsy. Histopathology, 35, 432-438. doi:10.1046/j.1365-2559.1999.035005432.x

[16] Tan, L.G.L. and Khoo, M.L.C. (2006) Accuracy of fine needle aspiration cytology and frozen section histopathology for lesions of the major salivary glands. Annals, Academy of Medicine, Singapore City, 35, 242-248.

[17] Kamal, M.M., Dani, A.A., Kotwal, M.N. and Kherdekar, M.S. (1994) Aspiration cytology of salivary gland lesions advantages and pitfalls. Indian Journal of Pathology and Microbiology, 37, 281-287.

[18] Patey, D.H. and Thackray, A.C. (1970) Infected adenolymphoma: A new parotid syndrome. British Journal of Surgery, 57, 569-572. doi:10.1002/bjs.1800570805

[19] Kern, S.B. (1988) Necrosis of a Warthin's tumor following fine needle aspiration. Acta Cytologica, 32, 207-208.

[20] Chan, J.K.C., Tang, S.K., Tsang, W.Y.W., Lee, K.C. and Batsakis, J.G. (1996) Histologic changes induced by fine-needle aspiration. Advances in Anatomic Pathology, 3, 71-90. doi:10.1097/00125480-199603000-00001

[21] Choreutaki, T., Scarpellini, F. and Eusebi, V. (1996) Breast cancer necrosis following fine needle aspiration biopsy. Tumori, 82, 242-244.

[22] Davies, J.D. and Webb, A.J. (1982) Segmental lymphnode infarction after fine needle aspiration. Journal of Clinical Pathology, 35, 855-857. doi:10.1136/jcp.35.8.855

[23] Tsang, W.Y.W. and Chan, J.K.C. (1992) Spectrum of morphologic changes in lymph nodes attributable to fine needle aspiration. Human Pathology, 23, 562-565. doi:10.1016/0046-8177(92)90134-O

[24] Kini, S.R. and Miller, J.M. (1986) Infarction of thyroid neoplasms following aspiration biopsy. Acta Cytologica, 30, 591.

[25] Kini, S.R. (1996) Post-fine-needle biopsy infarction of thyroid neoplasms: A review of 28 cases. Diagnostic $\mathrm{Cy}$ topathology, 15, 211-220.

doi:10.1002/(SICI)1097-0339(199609)15:3<211::AID-D C7>3.0.CO;2-J

[26] Batsakis, J.G., Sneige, N. and El-Naggar, A.K. (1992) Fine-needle aspiration of salivary glands: Its utility and tissue effects. Annals of Otology, Rhinology and Laryngology, 101, 185-188.

[27] Stephen, M.R., Matalka, I., Stewart, C.J.R. and Mackenzie, K. (1999) Xanthogranulomatous sialadenitis following diagnosis of Warthin's tumor: A possible complication of fine needle aspiration. Cytopathol, 10, 276-279. doi:10.1046/j.1365-2303.1999.00148.x

[28] Dardick, I., Jeans, M.T.D., Sinnott, N.M., Wittkuhn, J.F., Kahn, H.J. and Baumal, R. (1985) Salivary gland components involved in the formation of squamous metaplasia. American Journal of Pathology, 119, 33-43.

[29] Brannon, R.B., Fowler, C.B. and Hartman, K.S. (1991) Necrotizing sialometaplasia: A clinicopathologic study of sixty-nine cases and review of the literature. Oral Surgery, Oral Medicine, Oral Pathology, Oral Radiology, 72, 317- 
325.

[30] Bolat, F., Kayaselcuk, F., Erkan, A.N., Cagici, C.A., Bal, N. and Tuncer, I. (2004) Epidermoid carcinoma arising in Warthin's tumor. Pathology \& Oncology Research, 10, 240-242. doi:10.1007/BF03033769

[31] Gunduz, M., Yamanaka, N., Hotomi, M., et al. (1999) Squamous cell carcinoma arising in a Warthin's tumor. Auris Nasus Larynx, 26, 355-360. doi:10.1016/S0385-8146(99)00008-5
[32] Little, J.W. and Rickles, N.H. (1965) Malignant papillary cystadenoma lymphomatosum. Report of a case, with review of the literature. Cancer, 18, 851-856. doi:10.1002/1097-0142(196507)18:7<851::AID-CNCR2 $\underline{\text { 820180712>3.0.CO;2-7 }}$

[33] Ramzy, I., Rone, R. and Schantz, H.D. (1986) Squamous cells in needle aspirates of subcutaneous lesions: A diagnostic problem. American Journal of Clinical Pathology, 85, 319-324. 